Historic, Archive Document

Do not assume content reflects current scientific knowledge, policies, or practices. 
4 


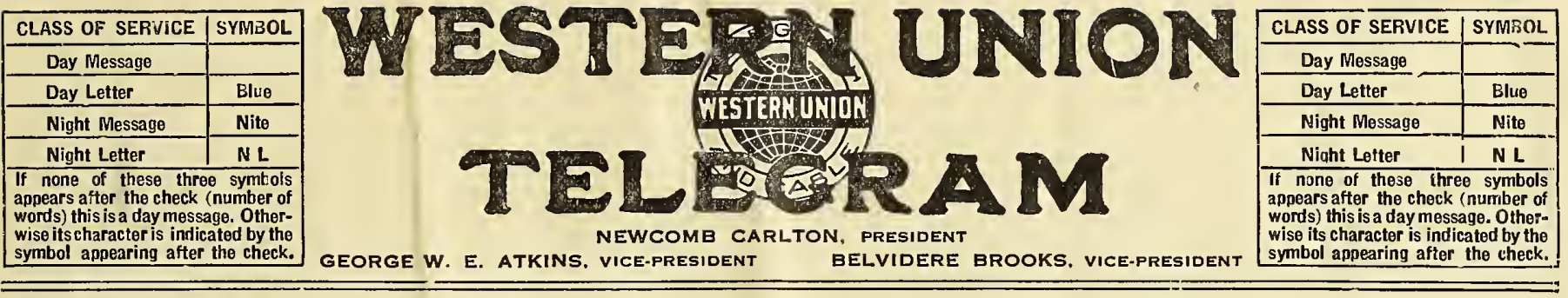

\section{RECEIVED AT}

A720M J 39 COLLECT NL ROCKY FORD COLO MAY 41917

WESTERN SEED \& IRRIGATION CO

FREMONT NEBR

GROWERS WILL ASK FOR THREE CENT ADVANCE ON ALL EXISTING CONTRACTS TOMORROW COYS HAVE AGREED TO INCREASE J C RORINSON WILL ATTEND MEETING TOMORROW GROWERS DECLARE THEY WILL NOT PLANT AT PRESNT PRICE ADVISE ME BY NOON TOMORROW

WILL MORRISON 
